\title{
Genetic and neurological foundations of customer orientation: field and experimental evidence
}

\author{
Richard P. Bagozzi • Willem J. M. I. Verbeke • \\ Wouter E. van den Berg • Wim J. R. Rietdijk • \\ Roeland C. Dietvorst $\cdot$ Loek Worm
}

Received: 15 February 2011 / Accepted: 27 June 2011 /Published online: 12 July 2011

(C) The Author(s) 2011. This article is published with open access at Springerlink.com

\begin{abstract}
We explore genetic and neurological bases for customer orientation (CO) and contrast them with sales orientation (SO). Study 1 is a field study that establishes that $\mathrm{CO}$, but not $\mathrm{SO}$, leads to greater opportunity recognition. Study 2 examines genetic bases for $\mathrm{CO}$ and finds that salespeople with $\mathrm{CO}$ are more likely to have the $7 \mathrm{R}$ variant of the DRD4 gene. This is consistent with basic research on dopamine receptor activity in the brain that underlies novelty seeking, the reward function, and risk taking. Study 3 examines the neural basis of $\mathrm{CO}$ and finds that salespeople with $\mathrm{CO}$, but not $\mathrm{SO}$, experience greater activation of their mirror neuron systems and neural processes associated with empathy. Managerial and research implications are discussed.
\end{abstract}

\author{
R. P. Bagozzi $(\bowtie)$ \\ Ross School of Business, University of Michigan, \\ 701 Tappan Street, \\ Ann Arbor, MI 48109-1234, USA \\ e-mail: bagozzi@umich.edu
}

W. J. M. I. Verbeke • W. E. van den Berg • W. J. R. Rietdijk • L. Worm

Department of Business Economics, Marketing H15-25, Erasmus School of Economics, Erasmus University Rotterdam, P.O. Box 1738, 3000 DR Rotterdam, The Netherlands

W. J. M. I. Verbeke

e-mail: Verbeke@ese.eur.nl

W. E. van den Berg

e-mail: Verbeke@ese.eur.nl

W. J. R. Rietdijk

e-mail: Verbeke@ese.eur.nl

L. Worm

e-mail: Verbeke@ese.eur.nl

R. C. Dietvorst

Department of Business Economics,

Erasmus School of Economics, Erasmus University Rotterdam, P.O. Box 1738, 3000 DR Rotterdam, The Netherlands
Keywords Knowledge brokering · Opportunity recognition - Genetics · Customer orientation . Neuroscience $\cdot$ Biomarkers $\cdot$ Personal selling · Marketing concept

"Everybody hates their phone," Jobs says, "and that is not a good thing. And there's an opportunity there." To Jobs' perfectionist eyes, phones are broken. Jobs likes things that are broken. It means he can make something that isn't and sell it to you at a premium price. ("The Apple of Your Ear," Time Magazine, Friday January 12, 2007)

In their visionary paper, Saxe and Weitz (1982) explore two contrasting orientations by which salespeople interact with customers: sales versus customer orientation. Under the former, salespeople are driven by such notions as, "I try to sell customers all I can convince them to buy, even if I think it is more than a wise customer should buy," where the motivation is to meet one's own short-term interests and goals and not necessarily the customer's. Under the latter, salespeople are guided primarily by such ideas as, "I try to align customers who have problems with products that will help them solve their problems," where the aim is to meet mutual needs and the hope is to build long-term relationships.

Sales orientation (SO) involves persuasion and "selling to" customers, whereas customer orientation (CO) is more about "interacting with" and encouraging customers to talk about their problems so that the salesperson can figure out their needs (a process akin to co-creation of solutions) and bring them in touch with solutions to their problem. Seldom has a concept sparked so much interest, resonating with both researchers and practitioners (e.g., Franke and Park 2006; Homburg et al. 2009; Leigh et al. 2001). 
Academics and sales managers are very interested in successfully selecting and managing salespeople, but to understand the basis for salesperson motivation and implement successful policies in this regard, they need to know the why behind $\mathrm{CO}$ and SO. Here is where the situation is muddled, for many anecdotal and loosely conceived explanations lack coherence and managerial relevance. Saxe and Weitz (1982) proposed that researchers should explore the psychological mechanisms underlying $\mathrm{CO}$, and indeed a plethora of selling and marketing research has attempted to do just this. For example, in their meta-study, Franke and Park (2006, pp. 693-695) suggested that CO is associated with the desire to maintain a long-term relationship with the customer, practicing the marketing concept, intrinsic motivation, empathic ability, and willingness to take risks (e.g., betting on uncertain long-term sales results instead of maintaining a short-term focus). These psychological explanations are rather at arm's length and reflect outside-in rationalizations, meaning that they rely on general, coarsegrained psychological mechanisms to explain overt behavioral orientations or tendencies. At first sight, they might seem ad hoc, incoherent, and difficult to comprehend and implement. Yet their face validity seems compelling. More finely grained explanations rooted perhaps in neuroscience and even genetic evidence are needed. Could diverse psychological explanations be supported by hard-wired biological mechanisms, which specifically activate when salespeople engage in $\mathrm{CO}$ as opposed to SO? Until now, the idea of using biological mechanisms to increase our understanding of salesforce behavior has not received much attention.

The goal of our research is to take a biological perspective on the role of $\mathrm{CO}$ versus $\mathrm{SO}$ in personal selling. We explore two biomarkers: one based on genetic analysis, the other based on neuroscience through the use of fMRI research. However, before we begin our investigation of biomarkers, it is important to demonstrate the phenomenon (phenotype) under investigation in the field (Kreek et al. 2005). This suggests evidence for external validity and provides targets for investigation by biological methods. Figure 1 presents an overview of our three studies. Study 1 shows that $\mathrm{CO}$ versus SO plays a role in the field, and Studies 2 and 3 examine the biological bases for CO and SO. In Study 1, we explore Saxe and Weitz's (1982) early conjecture that salespeople with CO adopt the marketing concept (p. 343) and that CO is especially beneficial for complex buying tasks (p. 348). We interpret these suggestions in a contemporary light: nowadays industrial salespeople operate as knowledge brokers in knowledge- intensive economies (e.g., Verbeke et al. 2011) and engage in opportunity recognition (Bonney and Williams 2009), which is defined as "efforts to make sense of signals of change [...] to form beliefs, whether or not enacting a course of action to address this change could lead to net benefits" (Gregoire et al. 2010, p. 415, emphasis in original removed; see also Bonney and Williams 2009). More specifically, in Study 1, we develop an opportunity recognition scale and test whether $\mathrm{CO}$ or SO predicts opportunity recognition.

Second, there is evidence in the basic science literature suggesting that opportunity recognition may have a genetic component in that novelty seeking, the functioning of the human reward system, and response to delayed gratification have been shown to be associated with the activation of the dopamine system in the brain (e.g., Dreber et al. 2009). Since dopamine receptors play an important role in the activation and regulation of the dopamine system, we focus on two genes that encode for these receptors, and which have been previously shown to affect dopamine system regulation (e.g., Nicolaou and Shane 2009). In particular in Study 2, we investigate whether $\mathrm{CO}$, but not $\mathrm{SO}$, is associated with genes known to affect dopamine regulation.

Third, Saxe and Weitz (1982, p. 344) posited that CO is related to "a concern for others," and Eades (2004) proposed the related notion that a successful salesperson should "feel the customers' pain" (see also Franke and Park 2006; Mayer and Greenberg 1964). Basic research in neuroscience has shown that empathic understanding involves the activation of the mirror neuron (MN) system in the brain, which, in a process termed synchronization, triggers other brain nuclei that function in empathic understanding (Cheng et al. 2009; Singer and Fehr 2005). In Study 3, we investigate the extent to which activation of the $\mathrm{MN}$ system of salespeople is related to $\mathrm{CO}$, but not $\mathrm{SO}$, using experimentation and fMRI procedures.

The paper is organized as follows. First, we present Study 1, our field study of the relation between CO and SO and opportunity recognition. Then comes Study 2, which examines genetic underpinnings of $\mathrm{CO}$ and SO. Third, we describe Study 3, which establishes the role of the MN system and empathy in $\mathrm{CO}$ and SO.

\section{Study 1: CO versus SO and opportunity recognition}

Saxe and Weitz (1982) noted that salespeople with high CO operate in a sense as mini-marketers during sales conversa-
Fig. 1 Overview model for variables and tests of hypotheses in Studies 1-3

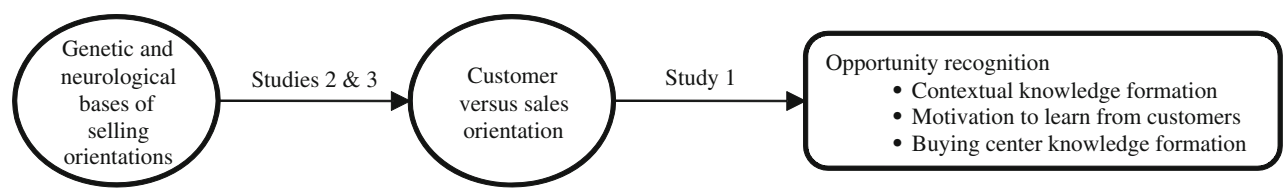


tions with customers. They enter sales conversations with such mindsets as "I try to get customers to discuss their needs with me." As we move into a knowledge-based economy, salespeople with high $\mathrm{CO}$ must spend time collecting information about customer needs and also demonstrate how their products - often complex solutions - can satisfy those needs. CO may not be correlated with work experience, per se (Franke and Park 2006, p. 700). We assume that salespeople with $\mathrm{CO}$, as opposed to $\mathrm{SO}$, constantly source knowledge (learn) both during and between sales conversations (e.g., visiting trade fairs or reading journals), such that they build insights (categories, solutions) that allow them to spot customer needs better (opportunity recognition) and connect those needs with their categories or solutions (knowledge brokering) (Bonney and Williams 2009; Gregoire et al. 2010; Verbeke et al. 2011). As salespeople interact with customers, they engage in analogical reasoning (Holyoak 1985), meaning that they look for similarities between what they see or hear (largely a bottom-up process) and what they know (top-down process) via mental representations. To the extent that salespeople seek to construct (or find) analogies during sales encounters, which involves situated cognition and awareness of contextual factors (Franke and Park 2006, p. 695; Homburg et al. 2009), they in turn passionately engage customers in stimulating, functional conversations, thus energizing discussions in intellectual and emotional ways. These processes result in a form of co-creation of solutions that is beneficial to both buyer and seller.

Business-to-business salespeople (the focus of our research) seldom meet with a single customer; rather, they meet with various members of a buying center. As salespeople interact with people in the buying center, they can uncover the idiosyncratic needs of these people and explore what drives them or how they view their problems and opportunities (e.g., Weitz and Bradford 1999). Doing this should enable salespeople to solve the different needs and pains of buying center members, or at least offer solutions. All this is consistent with the opportunity recognition process. In this spirit, we explore how salespeople engage in opportunity recognition.

\section{Opportunity recognition}

We constructed an opportunity recognition scale based upon Johnson et al.'s (2004) suggestion that people in marketing possess environmental knowledge in both functional and interactional senses. Three kinds of knowledge are relevant.

Contextual knowledge formation Opportunity recognition involves analogical reasoning that connects a target stimulus (e.g., a statement of need by the customer) to a source (a category or abstract framework that meets customer needs). Opportunity recognition entails aligning abstract insights derived from analyses of the industry, buyer, and own firm capabilities, product solutions, etc. with the concrete needs and issues of customers. Salespeople gather abstract knowledge on the industry and competition from such sources as customers (Bonney and Williams 2009), trade fairs, conferences, industry publications, and face-to-face contact with experts. Rodan and Galunic (2004) showed that knowledge heterogeneity (i.e., the variety of knowledge, know-how, and expertise derived from one's network) is positively related to performance and innovativeness. Key here is the idea that the abstract nature of the source content, where a wide range of abstract metaphors is used to recognize a situation, is both conducive to opportunity recognition and generates explicit "brain activation" in this regard (Gregoire et al. 2010, p. 417). High CO should foster knowledge formation, because as salespeople develop more abstract insights (generalizations), they remain curious about new developments and sensitive to threats and opportunities, and so they can make better connections between what customers communicate and their own general knowledge/ experience of the solutions needed and how to deliver them. CO thus implies that the salesperson who possesses broad experience relevant to sales practice will more likely recognize a customer's still dormant or vaguely specified needs. Equally, salespeople with a broad perspective give customers a way to validate their own ideas about the industry and product solutions, which is one way that salespeople function as knowledge brokers.

Note that sourcing information also involves tradeoffs and risk taking: time spent gathering knowledge might be better spent on actual selling (e.g., Saxe and Weitz 1982). Salespeople with SO should draw the line closer to actual selling than salespeople with CO. Indeed, salespeople with SO should allocate less resources to contextual knowledge gathering (because they are focused on convincing the customer to buy), and as a consequence they should learn less than salespeople with $\mathrm{CO}$ about how the customerseller gap can be bridged. Relative to salespeople with $\mathrm{CO}$, salespeople with SO place less emphasis on learning and exploration, and they prefer instead to emphasize "selling to," thereby painting an overly rosy picture of their services or pressuring customers into buying their solutions; this practice makes them, so to speak, "ego-centered tellers" and not "empathic sellers" (Richardson 1994).

Motivation to learn about customers High $\mathrm{CO}$ implies having natural curiosity and a readiness to uncover particular customer needs and determine how to meet those needs through the resources (products) of one's own firm (Saxe and Weitz 1982). Recognition of opportunities has two sides. From the customer's point of view, when customers feel that a salesperson cares about and understands their needs, they should experience psychological 
comfort (Edmonson and Woolley 2003; Tanner et al. 2008) and voice tacit needs more readily and in ways better understood by the salesperson. Those salespeople with high $\mathrm{CO}$ tend to be excited, curious, and vigilant when customers interact with them, even if only to make complaints or express concerns. Saxe and Weitz (1982) characterize this as the "free-flow of information," which is best exemplified by customers who ask challenging questions of salespeople, and salespeople who make suggestions for new product solutions to customers. Mercier and Sperber (2011) recently argued that analogical reasoning is largely motivational and occurs most naturally in two-way conversations. Quality interactions are needed to translate and reconcile abstract ideas with customer needs and validate customer judgments about competitive offers (Cross and Sproull 2004). When salespeople are perceived as knowledgeable about the market, they become trusted advisors, and the resulting solutions are in fact co-creations (Vargo and Lusch 2004).

In contrast, salespeople high in SO seek mainly to persuade customers, do not encourage customers to mention their own issues, and create fewer opportunities for psychological comfort; hence, their customers have less chance to express, let alone validate, their needs or issues than they would have interacting with salespeople high in CO.

Buying center knowledge formation In many selling situations, customers are multiple parties in buying centers with individual perceptions of their firm's actual requisites and constraints. To be effective, salespeople need to understand the reasons for all the different interpretations of a problem, factors inhibiting buying, and implications for sales. Moreover, salespeople should not only be aware of multiple points of view, but these in themselves should motivate salespeople to come up with tailor-made solutions that will have a greater buy-in for multiple parties in the buying center. Indeed, this is a key reason why tailor-made solutions proliferate.

For example, customers may readily recognize the functional value of a proposed solution, yet they may also suspect that it will have undesired implications from a political perspective (e.g., Dawes et al. 1998; Kohli 1989). However, in a knowledge-based economy, the political meaning of a proposed solution is not the only thing that counts. Members of the buying center should have the absorptive capacity to understand what a solution means to their firm in terms of its technical, financial, and organizational consequences as well.

Salespeople with high CO infer the various perspectives of pain or resistance to product adoption through the verbal and nonverbal cues given by customers in interpersonal interactions (Homburg et al. 2009). High CO leads salespeople to immerse themselves empathetically, through building informal networks, into the professional life of the buying center members and ask customers specific questions designed to gauge their absorptive capacity. It is precisely these insights (into pain or resistance, absorptive capacity) that allow them to co-create better solutions and learn why and how customers buy.

Salespeople with high SO focus on transmitting their own messages and are less interested in discovering the personal subtleties of members of the buying center; they learn relatively less than salespeople with high $\mathrm{CO}$ and may even alienate members of the buying center ("this salesperson does not care about or listen to us"). Hence, we propose the following hypotheses:

$\mathrm{H1}$ : The greater the CO, the greater the contextual knowledge formation effort, motivation to learn from customers, and implementation of buying center strategy.

$\mathrm{H} 2$ : SO will not relate significantly to contextual knowledge formation effort, motivation to learn from customers, and implementation of buying center strategy.

Figure 2 presents a structural equation model that summarizes the hypotheses.

\section{Method}

Thomas et al. (2001) developed a ten-item short-form SOCO scale, where five items measure sales orientation, and five items customer orientation. Using confirmatory factor analysis, Periatt et al. (2004) showed that a twofactor SOCO model fit their data well. We began our investigation with an attempt to replicate the ten-item version validated by Periatt et al. (2004). We found that seven of the original ten items proposed by Thomas et al. (2001) worked well but that three new items performed better than the three in the original short-form scale. Table 1 presents our own ten-item short form. We eliminated item 13 from the SOCO scale because it did not express an action, as do the other $\mathrm{CO}$ items (item 13 measures a state of mind). In addition, item 13 loaded unacceptably low (.40) on the $\mathrm{CO}$ factor in the confirmatory factor analysis by Periatt et al. (2004). We also eliminated item 16 from the SOCO scale because it is nearly identical to items 14 and 23 that are included, and it had the second lowest loading on the CO factor in the study by Periatt et al. (2004). In our exploratory factor analysis, items 13 and 16 loaded on other factors than the remaining short-form items. Instead, we used the first two items from the SOCO scale because they capture aspects of $\mathrm{CO}$ that were not well represented on the original short form. Namely, the new items measure attempts by the salesperson to give an accurate description of what a product can be expected to do for the customer, and get the customer talking about their needs. Items 1 and 2 loaded .40 and .71, respectively, on our exploratory factor analysis. 
Fig. 2 Causal model for testing effects of customer orientation and sales orientation on opportunity recognition dimensions (indicators of factors omitted for simplicity)

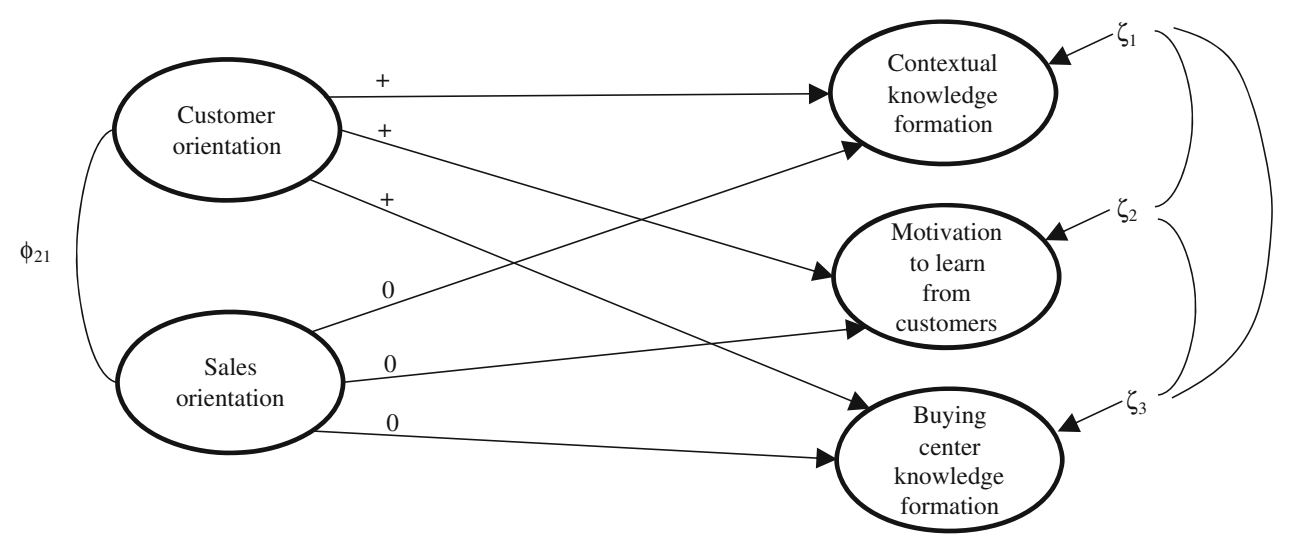

Predictions: $+=$ significant predictive relation; $0=$ non-significant predictive relation
On the SO short form, four of five items from the original scale worked well, but we eliminated item 22 and replaced it with item 3 . Item 22 in our exploratory factor analysis failed to load satisfactorily on any factor, whereas item 3 loaded .49 on SO.

We performed confirmatory factor analysis on the new short-form scale and found that the two-factor model fit very well: $\chi^{2}(1)=2.28, p=.13, \mathrm{NNFI}=.97, \mathrm{CFI}=.99$ and $\mathrm{SRMR}=.01$. The factor loadings for the $\mathrm{CO}$ factor ranged from .82 to .93 and for the SO factor from .82 to .87 . The two factors correlated -.58 with an s.e. $=.08$. Thus, the items for the new short form of SOCO measure both factors well and achieve discriminant validity. Next, all three scales for opportunity recognition (i.e., contextual knowledge formation, motivation to learn from customers, buying center knowledge formation) were administered along with the reduced versions of the $\mathrm{CO}$ and $\mathrm{SO}$ scales (see Tables 1 and 2).

Table 1 Items from the SOCO scale used in Study 1

\section{Customer orientation (CO)}

1. I try to get customers to discuss their needs with me.

2. I try to find out what kind of product would be most helpful to a customer.

3. I try to bring a customer with a problem together with a product that helps him solve the problem.

4. I try to give customers an accurate expectation of what the product will do for them.

5. I try to figure out what a customer's needs are.

Sales orientation (SO)

1. I try to sell a customer all I can convince him to buy, even if I think it is more than a wise customer would buy.

2. I try to sell as much as I can rather than satisfy a customer.

3. If I am not sure a product is right for a customer, I will still apply pressure to get him to buy.

4. I paint too rosy a picture of my products, to make them sound as good as possible.

5. It is necessary to stretch the truth in describing a product to a customer.
Our sample of 132 salespeople came from a variety of firms across multiple industries who participated in an executive education program at the collaborating university. The salespeople came from a variety of firms across multiple industries: $4 \%$ from automotive, $3 \%$ from food and beverage, $13 \%$ from banking, 3\% from utilities, $8 \%$ from manufacturing, $31 \%$ from professional services, $4 \%$ from pharmaceuticals, $2 \%$ from telecom, $5 \%$ from logistics, $16 \%$ from IT, $3 \%$ from retailing, $3 \%$ from energy, and $5 \%$ from other industries. The sample consisted of $71 \%$ men, $29 \%$ women, with an average age of 36.3 years (s.d. $=9.1$ ) and an average experience in selling of 10.4 years (s.d. $=8.0$ ).

The items for the three opportunity recognition scales were generated from interviews with salespeople and from the literature reviewed above. A total of 17 items was generated, but based on an exploratory factor analysis, two items were dropped because they cross-loaded too highly on multiple factors. Loadings on all factors ranged from .48 to .95 , and all cross-loadings for the 15 items were less than .25. They were pretested for clarity and relevance during seminars with other salespeople from similar industries. Table 2 shows the 15 items used in Study 1. Questionnaire items from the original English versions were translated into the language of the salespersons under study by one bilingual speaker, translated back into English by a second bilingual speaker, and then the original and the translation were compared to resolve discrepancies. The reliabilities for $\mathrm{CO}, \mathrm{SO}$, and the three dimensions of practical opportunity recognition are $.84, .79$, and $.79, .77$, and .79 , respectively.

Results

We ran a structural equation model on the data corresponding to Fig. 2, where two indicators per factor were developed by parceling items; the procedures and criteria were discussed in Bagozzi and Heatherton (1994) and Bagozzi and Edwards (1998). The overall model fit well: $\chi^{2}(25)=27.69, p=.35$, 
Table 2 Items from the opportunity recognition scale used in Study 1
Contextual knowledge formation

\begin{tabular}{|c|c|}
\hline 1. & I try to keep up by reading journals related to my industry. \\
\hline 2. & $\begin{array}{l}\text { I ask myself what the important issues in my work are and then I ask how new information } \\
\text { fits into this framework. }\end{array}$ \\
\hline 3. & I combine my experiences and insights concerning the industry in which I work. \\
\hline 4. & I gather knowledge from my industry from different perspectives. \\
\hline 5. & I regularly talk to people working in my industry to keep up with new developments. \\
\hline 6. & I study my competitors at trade fairs and conferences. \\
\hline \multicolumn{2}{|c|}{ Motivation to learn from customers } \\
\hline 1. & $\begin{array}{l}\text { I feel stimulated to come up with new ideas when customers or people in the buying center } \\
\text { express their thoughts and ideas. }\end{array}$ \\
\hline 2. & I notice that many of my ideas are generated by customers asking me challenging questions. \\
\hline 3. & When customers make suggestions or make complaints I seek to learn from them. \\
\hline 4. & When customers ask me difficult and challenging questions I get stimulated. \\
\hline 5. & When customers ask me challenging questions, I feel as if I am in the flow. \\
\hline \multicolumn{2}{|c|}{ Buying center knowledge formation } \\
\hline 1. & $\begin{array}{l}\text { I seek to find out in detail what training members of the buying center have had and how } \\
\text { they keep up with the developments in their industry. }\end{array}$ \\
\hline & I try carefully to gauge the influence of a specific person in the buying process. \\
\hline & I try to get gauge to what extent customers act as professionals. \\
\hline & I always ask how people in the buying center really perceive us. \\
\hline
\end{tabular}

$\mathrm{NNFI}=1.00, \mathrm{CFI}=1.00$, and $\mathrm{SRMR}=.026$. Factor loadings for $\mathrm{CO}$ were .83 and .93 , SO were .78 and .86 , contextual knowledge were .95 and .93 , learning from customers were .84 and .91, and buying center learning were .90 and .80; all error terms were significant but very low in value. Importantly, CO significantly predicted contextual knowledge formation $(\gamma=.75, t=5.42$, std $\gamma=.59)$, motivation to learn from customers $(\gamma=.65, t=4.30$, std $\gamma=.55)$, and buying center knowledge formation $(\gamma=1.01, t=5.15$, std $\gamma=.64)$, whereas SO failed to significantly predict contextual knowledge formation $(\gamma=.05, t=.58$, std $\gamma=.06)$, motivation to learn from customers $(\gamma=-.05, t=-.49$, std $\gamma=-.06)$, and buying center knowledge formation $(\gamma=-14, t=$ -1.10 , std $\gamma=-.13)$. The explained variance estimates showed $R^{2}=.40$ for contextual knowledge formation, $R^{2}=.26$ for motivation to learn from customers, and $R^{2}=.33$ for buying center knowledge formation. Multiple regression analysis showed that $\mathrm{CO}$ and $\mathrm{SO}$ did not interact significantly $(\beta=-.02, t=-.27$ for contextual knowledge formation; $\beta=.03, t=.44$ for motivation to learn from customers; $\beta=-.02, t=-.21$ for buying center knowledge formation).

\section{Discussion}

Customer orientation, especially salient for complex products in knowledge-intensive economies, requires salespeople to seek sources of industry-related knowledge, learn from customers, and try to understand the different perspectives of buying center members (all of which are aspects of opportunity recognition). Salespeople who engage in opportunity recognition try to get customers to discuss their needs with them. Figuring out which product would be most helpful for the customer is a typical tactic of customer-oriented salespeople. The findings show that $\mathrm{CO}$ is related to opportunity recognition, whereas $\mathrm{SO}$ is not.

The next study takes a biological perspective in seeking to understand genetic bases for $\mathrm{CO}$ dimensions associated with the diligent, empathic search for new nuances when interacting with customers. $\mathrm{CO}$, such as might be reflected in how members of the buying center consider and frame their needs, can be seen to reside in certain biomarkers, especially those involved in the dopamine system. We develop this perspective below.

\section{Study 2: Genetic analysis of customer versus selling orientation}

[DRD4 gene] children have their own strengths and limitations: they don't do well in the school environment of repetition, auditory learning, and rote memorization that has been set up for "normal" kids, and they don't make very good bookkeepers or managers. Genetically these kids are pioneers, explorers, and adventurers. They make great innovators, and they find high levels of success in any field where there's a lot of change, constant challenge, and lots of activity. Such personalities are common among 
emergency room physicians, surgeons, flight pilots, and salespeople. (Hartmann and Palladino 2004, p. 6)

In the field of entrepreneurship, a pioneering study has found that the ability to identify business opportunities has a genetic component (e.g., Nicolaou and Shane 2009). Nicolaou et al. (2008) conjecture that people carrying the DRD4 gene have greater sensitivity to certain environmental stimuli, akin to what psychologists call novelty seeking or sensation seeking. Novelty seeking refers to the need for varied, novel, and complex experiences and the willingness to take physical and social risks for the sake of such an experience (Zuckerman 1994). The focus here is not to understand novelty seeking per se, but to determine whether it functions as a mechanism that motivates salespeople to engage customers in discussing and figuring out their needs, so that solutions can be effectively presented. As Study 1 showed, this is associated with opportunity recognition.

Novelty seeking is influenced by the dopamine system in the brain. Also known as the reward system, the dopamine system tags behavioral strategies and their consequences, as well as changes in the environment such as opportunities, with incentive salience (Berridge and Robinson 1998). Two genes, encoding for dopamine receptor 4 (DRD4) and dopamine receptor 2 (DRD2), regulate dopamine signaling in the brain. Specific variants of these genes have been shown to increase the salience of information, which plays a role in opportunity recognition processes (Nicolaou et al. 2008). Anatomically, the dopamine signaling pathways include such brain structures as the ventral tegmental area, nucleus accumbens, striatum, and the prefrontal cortex. These regions are activated when people feel motivated and anticipate satisfaction in learning (e.g., Berns 2005). In other words, dopamine signaling is related more to the anticipation of a reward than to the actual receipt of a reward.

The goal of Study 2 is to investigate whether there is a specific association between variants of the DRD4 and $D R D 2$ genes and $\mathrm{CO}$ and $\mathrm{SO}$. A targeted study in genetics requires the development of robust hypotheses, based upon the biological mechanisms in which the genes of interest function. As mentioned above, common genetic variability in the $D R D 4$ and $D R D 2$ genes has been found to have a functional impact in the regulation of the dopaminergic system and is implicated in behaviors such as risk taking, novelty seeking, addiction, and impulsivity (Dreber et al. 2009; Ebstein et al. 1996; Eisenberg et al. 2007). Yet there are also functional differences.

\section{DRD4}

The DRD4 gene has attracted much attention lately in the popular press where Hartmann and Palladino (2004) termed it the "Edison" gene, referring to its implications for enhancing people's ability to engage in divergent thinking (novelty seeking) and consequently remain engaged in tasks that they are interested in (Cloninger 2004, p. 304; Hallowell and Ratey 1994). It is exactly this divergent, exploratory, and discovering ability that should be related to spotting business opportunities and persistently seeking to pursue such goals (incentive salience). This insight translates well into what has further been elaborated on by Nicolaou et al. (2008), namely, that the association between the DRD4 receptor gene and novelty seeking found by Ebstein et al. (1996) should spill over to other contexts, such as entrepreneurship and creative selling. People with the $D R D 4$ gene should be more sensitive than others to new information about potential business opportunities. That is, the DRD4 gene interacts with information about opportunities to increase the likelihood that a person will identify a new business idea, and so increase the probability that the person will engage in opportunity recognition as described and found in Study 1.

The 7-repeat (7R) variant of the DRD4 gene is believed to have the greatest effect on this behavior. Carrying the $7 \mathrm{R}$ variant has been associated recently with the traits of novelty seeking, risk taking, and behavioral disinhibition (Congdon et al. 2008; Dreber et al. 2009; Ebstein et al. 1996). Based upon these findings and the notion that entrepreneurs are more action oriented and prefer engaging in multiple activities simultaneously (Baron and Ward 2004), Nicolaou and Shane (2009) speculated that the likelihood for a person to engage in entrepreneurial activity might be influenced by variation in the DRD4 gene. We propose that similar mechanisms drive the opportunity recognition behavior found in high $\mathrm{CO}$ salespeople, and we therefore conjecture that carrying the $7 \mathrm{R}$ variant of the $D R D 4$ gene contributes to the extent to which salespeople display a natural curiosity toward understanding how customers' problems match firms' solutions. Consequently, salespeople with the $7 \mathrm{R}$ variant of the $D R D 4$ gene should score higher on CO than salespeople without the $7 \mathrm{R}$ variant. The opposite should occur for SO: people with the $7 \mathrm{R}$ variant should score lower on SO than those without the $7 \mathrm{R}$ variant. Thus,

H3: Salespeople with the 7R variant of the DRD4 gene should score higher on $\mathrm{CO}$ (lower on $\mathrm{SO}$ ) than those without the $7 \mathrm{R}$ variant.

\section{DRD2}

Variability in the DRD2 gene has been shown to modulate dopamine activity in the brain. Previous findings show that the less frequent A1 version of this gene is associated with addictive disorders and antisocial traits. Due to a reduced dopamine response to pleasurable stimuli (such as drugs, alcohol, or food), carriers of the A1 
variant require and seek more stimulation. In addition, these individuals favor immediate gratification rather than longterm rewards (see Dreber et al. 2009, p. 89). Further, the cognitive inflexibility of A1 carriers should relate to the salesperson's unwillingness to switch strategies. For example, "Even if I am not sure a product is right for a customer, I will still apply pressure to get him to buy" (item 3 in the SO scale) suggests a rigid strategy for salespeople with SO. Salespeople with high CO invest more in understanding customers, which in turn might result in more long-term relationship gains and fewer immediate rewards than would be expected for salespeople with high SO. Since CO should lead to building sustainable relationships with customers, whereas SO need not, we hypothesize:

H4: Salespeople with the A1 variant of the DRD2 gene should score higher on SO (lower on $\mathrm{CO}$ ) than those without the A1 variant.

Method

Salespeople $(n=65)$ working in B2B environments were asked to participate in a study involving DNA analysis. They came from the following industries: $4 \%$ from automotive, $3 \%$ from food and beverage, $15 \%$ from banking, 3\% from utilities, $9 \%$ from manufacturing, $23 \%$ from professional services, $7 \%$ from pharmaceuticals, $2 \%$ from telecom, $5 \%$ from logistics, $20 \%$ from IT, $3 \%$ from retailing, and $6 \%$ from other industries. Respondents answered an online questionnaire containing $\mathrm{CO}$ and $\mathrm{SO}$ questions from the SOCO scale (see Table 1). The average age was 34 years $($ s.d. $=5.8)$. The alphas of the $\mathrm{CO}$ and $\mathrm{SO}$ scales were .72 and .64 , respectively.

We followed recommended practice to gather DNA data and analysis, and allele frequencies analysis using the Hardy-Weinberg Equilibrium. For further details, please see Technical Appendix 1.

We used parametric $t$-tests for equality of means on the five-item $\mathrm{CO}$ scale and five-item SO scale and DRD2/DRD4 polymorphisms of participants (see Technical Appendix 1, and Tables 3 and 4).

Results

Tables 5 and 6 present the results of the statistical tests. Significant differences were found for the effects of the $7 \mathrm{R}$ variant of the DRD4 gene on $\mathrm{CO}$, as hypothesized. The test on differences in means between salespeople with no $7 \mathrm{R}$ forms of the DRD4 gene $(M=5.87)$ and those with one or more 7-repeat forms $(M=6.24)$ is significant at a $5 \%$ significance level $(p=.04)$. The box plot in Fig. 3 shows the difference in distribution between the two samples, with the two-allele frequency groups on the $\mathrm{X}$-axis and the
Table 3 DRD4 48 bp VNTR allele frequencies, genotypes, genotype and classifications $(\mathrm{N}=65)$

\begin{tabular}{|c|c|c|}
\hline Allele & $\mathrm{N}$ & $\%$ \\
\hline \multicolumn{3}{|l|}{ Allele } \\
\hline 2 & 8 & $6.2 \%$ \\
\hline 3 & 2 & $1.5 \%$ \\
\hline 4 & 91 & $70.0 \%$ \\
\hline 5 & 1 & $0.77 \%$ \\
\hline 7 & 25 & $19.2 \%$ \\
\hline 8 & 3 & $2.3 \%$ \\
\hline Total & 130 & $100 \%$ \\
\hline \multicolumn{3}{|c|}{ Genotype } \\
\hline $2 / 2$ & 1 & $1.54 \%$ \\
\hline $4 / 2$ & 5 & $7.69 \%$ \\
\hline $4 / 3$ & 2 & $3.08 \%$ \\
\hline $4 / 4$ & 30 & $46.15 \%$ \\
\hline $4 / 5$ & 1 & $1.54 \%$ \\
\hline $7 / 2$ & 1 & $1.54 \%$ \\
\hline $7 / 4$ & 20 & $30.77 \%$ \\
\hline $7 / 7$ & 2 & $3.08 \%$ \\
\hline $8 / 4$ & 3 & $4.62 \%$ \\
\hline Total & 65 & $100.00 \%$ \\
\hline \multicolumn{3}{|c|}{ Genotype Classification $^{\text {a }}$} \\
\hline No $7 \mathrm{R}$ & 39 & 57.97 \\
\hline $7 \mathrm{R}$ & 26 & 42.03 \\
\hline Total & 65 & $100 \%$ \\
\hline
\end{tabular}

${ }^{\mathrm{a}}$ Allele frequencies are in HWE

$(\chi 2=0.3915, p$-value $=0.5315$, one-sided $)$

$\mathrm{CO}$ scores on the Y-axis. The test results on the difference in means between salespersons with the A1 variant form of dopamine receptor 2 (DRD2) is not significant with respect to $\mathrm{SO}(p=.99)$ but approached significance for $\mathrm{SO}$ $(p=.07)$.

\section{Discussion}

As predicted, we found a significant association between the presence of the 7R allele of the DRD4 gene with $\mathrm{CO}$ and no association with SO. This is consistent with research that shows a correlation between the $D R D 4$ gene and both novelty seeking (Munafo et al. 2008) and risk taking in financial contexts (Dreber et al. 2009). Moreover, the analyses showed a marginally significant effect of the $\mathrm{A} 1$ variant of the $D R D 2$ gene on $\mathrm{SO}$, but no significant effects of the A1 variant of the $D R D 2$ gene were found on $\mathrm{CO}$, as expected. A positive finding between $\mathrm{SO}$ and the $\mathrm{A} 1$ variant of $D R D 2$ is consistent with basic research findings showing that the $D R D 2$ gene may be implicated in immediate reward striving and impulsiveness (e.g., Dreber et al. 2009, p. 89; McClure et al. 2004). 
Table 4 DRD2 Taq1a allele frequencies, genotypes, genotype and classifications $(\mathrm{N}=65)$

\begin{tabular}{lrl}
\hline Allele & $\mathrm{N}$ & $\%$ \\
\hline Allele & 37 & \\
A1 (T) & 93 & $28.5 \%$ \\
A2 (C) & 130 & $71.5 \%$ \\
Total & & $100.0 \%$ \\
Genotype & 7 & \\
A1/A1 & 23 & $10.77 \%$ \\
A1/A2 & 35 & $35.38 \%$ \\
A2/A2 & 65 & $53.85 \%$ \\
Total & & $100.00 \%$ \\
Genotype Classification ${ }^{\text {a }}$ & 35 & \\
No A1 & 30 & $53.85 \%$ \\
A1 & 65 & $46.15 \%$ \\
Total & & $100 \%$ \\
\hline
\end{tabular}

${ }^{a}$ Allele frequencies are in HWE

$(\chi 2=1.1165, p$-value $=0.29065$, one-sided $)$

We argue that these two traits are not conducive to the personal selling role under consideration, which requires planning, persistence, and valuation of delayed rewards.

In sum, the findings show that $\mathrm{CO}$ is clearly associated with the $7 \mathrm{R}$ allele of the DRD4 gene, a biomarker that suggests why salespeople with high $\mathrm{CO}$ are more likely to thrive when they interact with customers (intrinsic pleasure), show persistent curiosity, and get excited when talking with customers; that is, these salespeople are curious, seek novelty, and are intrinsically motivated. SO salespeople are associated with the A1 variant of the DRD2 gene, which suggests they prefer immediate gratification and are cognitively inflexible, two traits not conducive to favorable opportunity recognition.

\section{Study 3: Neurological processes underpinning social interactions}

In Study 3, we investigate the relationship between SO and $\mathrm{CO}$ and associated neural activity in an fMRI experiment.

Table 5 Statistical $t$-test-DRD4 $48 \mathrm{bp} \mathrm{VNTR} t$-test for equality of means (equal variances assumed)

\begin{tabular}{lllcc}
\hline & Group & Mean & $t$-test (two-sided) & $p$-value \\
\hline Customer orientation & No 7R & 5.87 & $\mathbf{- 2 . 1 2}$ & $\mathbf{0 . 0 4}$ \\
& 7R & 6.24 & & \\
Selling orientation & No 7R & 5.41 & 0.35 & 0.73 \\
& $7 \mathrm{R}$ & 5.34 & & \\
\hline
\end{tabular}

${ }^{\text {a }}$ Bold values are significant at a 5\% significance level
Table 6 Statistical $t$-test-DRD2 Taq A1 $t$-test for equality of means (equal variances assumed)

\begin{tabular}{lllcc}
\hline & Group & Mean & $t$-test (two-sided) & $p$-value \\
\hline Customer orientation & No A1 & 6.02 & 0.01 & 0.99 \\
& A1 & 6.02 & & \\
Selling orientation & No A1 & 5.23 & -1.83 & 0.07 \\
& A1 & 5.59 & & \\
\hline
\end{tabular}

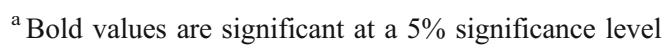

Salespeople with high CO are thought to operate as minimarketers when they interact with customers. Salespeople ought to be passionate about discovering customers' needs/ problems and solving these problems using their store of knowledge (memory, analogical reasoning). The passion to discover and solve their customers' needs was expressed nicely by Levitt (1986) when he described the qualities of the marketing imagination:

Imagination means to construct mental pictures of what is or is not actually present, what has never been actually experienced. [...] It consists simply of letting themselves live, as it were, in their customer's shoes, talking their language, thinking their thoughts, feeling their emotions, responding to their cues.... (Levitt 1986, pp. 130, 134, emphasis added)

In what follows, we focus on what is entailed in discovering customers' needs (or resistance and pains) when salespeople let themselves live "in their customer's shoes." There are two aspects to discovering these needs. There is the general ability to sense that the customer is in pain or resistant to persuasion, but there is also the refined ability to feel or imagine "the customer's actual pain" such that a salesperson can seek a solution for it

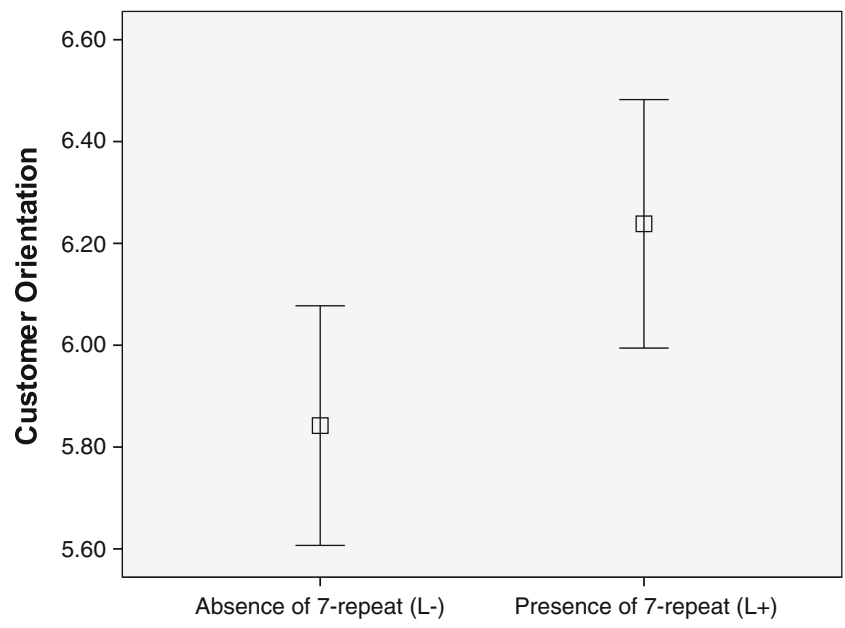

DRD4 Polymorphism

Fig. 3 Box plot of customer orientation and DRD4 
(analogical reasoning). Franke and Park (2006, p. 695) as well as Homburg et al. (2009) note that empathy might be an important driver of $\mathrm{CO}$, since it involves being aware of situational factors linked to customers' pain. Equally, Saxe and Weitz (1982, p. 344) conjecture that SO involves a concern for self, whereas $\mathrm{CO}$ involves a concern for others (Blake and Mouton 1970).

The empathy response arises from the comprehension of another person's emotional state, especially negative emotions (e.g., Eisenberg 2000). From the classic psychological perspective, empathy consists of three components: (1) an emotional reaction that might include sharing the other's feelings; (2) a cognitive capacity to take the perspective of the other; and (3) a monitoring mechanism that registers the source of the experienced affect in a way that differentiates the self from the other (Lamm et al. 2007, p. 42). In what follows we link these psychological components of empathy to neural mechanisms:

The emotional response associated with empathy can be one of two kinds. Empathic concern consists of focus on the plight of another person and feeling compassion-like or sympathetic-like emotions. Personal distress consists of a projection of the self into an aversive situation and feeling fear-like emotions. The insula, anterior medial cingulated cortex (aMCC), and the amygdala are three key brain regions that are activated in emotional aspects of empathy (Decety and Lamm 2006, p. 1152).

Decety and Lamm (2006, p. 1151) point out that taking the perspective of another person "allows us to overcome our usual egocentricism, tailor our behavior to others' expectations, and thus make satisfying interpersonal relations possible" (see also Davis 1994). When people take the perspective of others, similar neural circuits are activated in the self, as in the other person undergoing the experience or action under observation. We will discuss the common neural processes in the next section. For now, we wish to point out that perspective taking entails top-down information processing (executive functions), which regulates cognition and emotion through such processes as selective attention and self-regulation. The executive functions occur in parts of the prefrontal cortex, such as the medial region, and in the inferior parietal lobule (e.g., Decety and Jackson 2004; Decety and Lamm 2006, p. 1151). The precuneus region has been implicated in perspective taking as well (e.g., Cavanna and Trimble 2006; Vogeley et al. 2001).

The monitoring mechanism of empathy, which registers the source of experienced affect in terms of selfother, is important for differentiating empathic concern from emotional distress, where the former is part of the meaning of empathy, and the latter is a personal reaction not constitutive of empathy. In other words, empathy is an other-oriented emotional reaction, but personal distress is a self-oriented emotional reaction. As Decety and Lamm (2006) note:

[I]n the experience of empathy, individuals must be able to disentangle their own feelings from the feelings shared with others to attribute mental states to the target. Self-awareness is a necessary condition for making inferences about the mental states in others.... Therefore, 'agency' is a crucial aspect for successfully navigating shared representations between self and other.... [T] he ability to recognize oneself as the agent of a behavior is the way one builds as an entity independent from the external world.... [A]ffective sharing must be modulated and monitored by the sense of whose feelings belong to whom..., and thus, agency is a crucial aspect that enables a selfless regard for the other rather than a selfish desire.... (Decety and Lamm 2006, p. 1154)

The balance between self and other perceptions and the experience of agency has been observed in the inferior parietal lobule (e.g., Decety and Lamm 2007). We infer from this basic research that salespeople who practice either $\mathrm{SO}$ or CO selling are likely to experience different neuronal activity relations when observing emotions, but the neural mechanisms behind this capability remain largely to be explored. Wheng (2009) recently found that self-reports of empathy were related to activation of the pars opercularis. Therefore, our aim in this study is to explore to what extent salespeople's scores on $\mathrm{CO}$ and $\mathrm{SO}$ relate to neural systems, particularly the MN system. Given the other-oriented focus of $\mathrm{CO}$ and the self-oriented focus of $\mathrm{SO}$, we expect that $\mathrm{CO}$ will relate to the $\mathrm{MN}$ system and empathy, but $\mathrm{SO}$ will be unrelated.

Gallese (2003) noted that important neural nuclei are involved in empathic understanding in the MN system. Invested with motor properties, MNs are found in the premotor cortex and the posterior parietal cortex. They fire not only during the execution of one's own actions but also while observing somebody else's (Iacoboni 2009, p. 659). Oberman and Ramachandran (2007) note that MNs play a key role in the neural circuitry underlying the simulation of social understanding; they called this the simulation account of empathy.

\section{Hypotheses}

Following the line of reasoning as given in the neuroscience literature reviewed above, we propose several hypotheses concerning the relationship of activation of specific regions with $\mathrm{SO}, \mathrm{CO}$, and the $\mathrm{MN}$ system.

Mirror neuron coordination We predict that the MN system functions in an automatic, bottom-up manner to produce emotional sharing and the interpretation of the intentions of 
others with whom one interacts. Recent research identifies several key brain regions in this regard (e.g., Carr et al. 2003; Gallese 2003; Iacoboni and Dapretto 2006):

H5: The greater the $\mathrm{CO}$, the greater the coordinated activation of the posterior inferior frontal cortex, Broca's area, and anterior inferior parietal lobule. SO is expected to show no significant relationships with activation in these brain regions.

Coordinated activation here and below simply means that the indicated brain regions are activated together as an ensemble of responses. No claim is made that activation of one region leads to activation of other regions.

Empathy We predict that $\mathrm{CO}$ will be associated with greater empathy, as reflected in the psychological components discussed above. For taking the perspective of another person, we draw on the following studies to identify the appropriate regions of the brain: Decety and Lamm (2006), Cavanna and Trimble (2006), and Vogeley et al. (2004).

H6: The greater the $\mathrm{CO}$, the greater the coordinated activation of the medial prefrontal cortex (mPFC), the precuneus, and the right inferior parietal cortex regions of the brain. $\mathrm{SO}$ is expected to show no significant relationships with activation of these brain regions.

Empathic concern In this bottom-up emotional response, a number of brain regions have been implicated (e.g., Carr et al. 2003; Decety and Lamm 2006).

H7: The greater the $\mathrm{CO}$, the greater the coordinated activation of the insula and amygdala regions of the brain. SO is expected to show no significant relationships with activation of the brain regions.

Self-other monitoring mechanism Several brain regions have been identified with this mechanism, which regulates the proper other-oriented emotional reactions constitutive of empathy (e.g., Decety and Lamm 2007):

H8: The greater the $\mathrm{CO}$, the greater the coordinated activation of the inferior parietal lobule. SO is expected to show no significant relationship with activation of this brain region.

Method

From the sample of 132 salespeople in Study 1-94 men and 29 women who worked across the industries described in Study 1; average age was 36.3 years (s.d.=9.1) and selling experience 10.4 years $($ s.d. $=8.0)$-we selected participants on the basis of a wide range of scores on the ten-item shortform SOCO scale. Twenty-four healthy right-handed volunteers (16 men, 8 women; average age 34.4 years, s. $\mathrm{d} .=6.13$ ) were selected for participation in the fMRI part of the experiment, for which the top 12 and bottom 12 scorers on the total SOCO scale were selected, consistent with common practice in similar fMRI studies. The 24 salespeople came from the following industries: two from food and beverage, one each from manufacturing, pharmaceuticals, telecom, and logistics, six from professional services, five from IT, two from retailing and five from other industries. Participants provided informed written consent, and the local research ethics committee approved the experiment. Participants were not told about the aim of the study before the experiment but were informed after its completion.

Observing and executing facial expressions evokes activity in a neural network extending from the inferior frontal gyrus (parse opercularis), temporal parietal junction, superior temporal sulcus, insula, and amygdala (Dapretto et al. 2006; van der Gaag et al., 2007). These findings show that the same neural structures that are active during execution of facial expressions are also active when the same facial expressions are observed in others.

In order to test that the activity in regions that show significant correlations with $\mathrm{CO}$ measures are specifically due to the mirroring properties of these regions, subjects participated in two experiments. First, subjects were asked to simply observe a number of actors displaying basic emotions, neutral faces, and moving geometrical shapes (MNS task). In the next experiment, subjects were asked to imitate the same emotional expressions following a green -X- and observe emotional expressions following a red -X- (imitation task). The goal of the first task during scanning was to measure individual differences in the amount of MN activity. Van der Gaag et al. (2007) showed that although MN activity is automatically triggered by viewing facial expressions, the amount of activation is not immune to attention modulation (e.g., asking participants to imitate a facial expression during a later stage increased the amount of $\mathrm{MN}$ activity). In order to ensure that we captured spontaneous activations, subjects were unaware of the imitation task that followed the first MNS task. Most MN experiments involve trials where participants are asked to imitate the facial expressions they are observing (besides asking participants to observe facial expressions and neutral faces passively). The imitation task is conducted to demonstrate that observation and execution evoke activity in the same neural structures.

However, our interest lay in the individual differences in the amount of MN activity between high and low $\mathrm{CO}$. These differences in MN activity are captured when activity during observing facial expressions is compared with 
activity during observing neutral faces or moving geometric shapes. Therefore, in the present context the imitation task played a different role. It served as a control experiment in which we made use of the opportunity to evoke activity in many of the same neural structures as during the MNS task. For the imitation task the activity during imitating facial expressions was compared with activity during observing facial expressions passively. This comparison captured motor activity involved in the execution of facial expressions, and not MN activity (because subjects viewed facial expressions during both observe and imitation conditions, mirror neurons are evoked to a similar extent). So finding regions in the $\mathrm{MN}$ system that correlate significantly with CO only during the MNS task and not during the imitation task would provide additional evidence that $\mathrm{CO}$ scores are related specifically to the mirroring properties of these regions. However, finding similar regions in which activity correlates significantly with $\mathrm{CO}$ scores for both MNS task and imitation task could mean that these correlations are the result of differences in brain activity regardless of the mirroring properties of these regions.

For information on the technical aspects of the fMRI stimuli, research design, and procedures, as well as the associated statistical analysis, please refer to Technical Appendix 2.

We examined the correlations of both $\mathrm{SO}$ and $\mathrm{CO}$ with brain activity within the contrasting context of negative minus neutral stimuli. These statistical analyses follow standards in the neuroscience literature and help us test the hypotheses concerning brain activations given a salesperson's scores on the $\mathrm{CO}$ and $\mathrm{SO}$ items, as proposed above.

\section{Results}

The most important, interpretable findings occur for contrasts in the observation of negative minus neutral emotional expressions. Associations between $\mathrm{CO}$ scores and brain region activation for these contrasts showed 11 regions achieving significant results. Table 7 summarizes the findings for nine of these regions, while Fig. 4( $a$ and $b$ ) shows the spatial location of the activations. All associations between SO scores and brain region activations were non-significant and are therefore not presented in the tables and figures.

An important point to note is that the $r$ values in the last column of Table 7 represent the correlation coefficients between the activation levels of the noted brain areas and the $\mathrm{CO}$ items (positive correlation: the higher the score on $\mathrm{CO}$ items, the higher the activation in a particular area). The correlations between SO scores and activation levels are excluded as none was significant.

Rows 1-4 in Table 7 present the results for the primary mirror neuron system, which is located in the posterior part of the inferior frontal gyrus and the anterior part of the inferior parietal lobule. Along with the right temporal parietal junction (e.g., Decety and Lamm 2007), these two areas have been implicated in empathy and recognition of intentionality (e.g., Gallese 2003; Iacoboni and Dapretto 2006). In addition, the supplemental motor area is involved in the planning and control of motor actions (e.g., Nachev et al. 2008). The results show significant positive correlations with $\mathrm{CO}$ scores: right supplemental motor area ([2-2 52], $r=.55, p<.01)$, right precentral gyrus ([62 6 24], $r=.72, p<.01$ ), right postcentral gyrus ([48-20 62], $r=.67, p<.01$ ), and right pars opercularis/ pars triangularis, also known as Broca's area ([62 6 62 22], $r=.72, p<.01$ ).

Rows 5-6 present the findings for the precuneus region, which is implicated in top-down (executive) processing related to perspective taking and self-other differentiation (e.g., Cavanna and Trimble 2006). The results show significant positive correlations with $\mathrm{CO}$ scores: right precuneus ([10-76 42], $r=.57, p<.01$ ), and left precuneus ([-12 -42 76], $r=.57, p<.01)$.

Rows 7-8 depict the inferior and superior parietal lobule and their statistics ([26, $-56,50], r=.54, p<0.010$ and $([-46,66,68], r=0.68, p<0.01)$. Both are important areas in the perception of the stimuli by participants. The correlation coefficients indicate that participants scoring high on the $\mathrm{CO}$ items also show more activation in these areas.

The final result in Table 7 (row 9) is for the fusiform gyrus, which registers perception and attention paid to human faces (e.g., McCarthy et al. 1997; Wojciulik et al. 1998). The findings show a significant positive correlation with $\mathrm{CO}$ scores: left fusiform gyrus ([-34-76-16], $r=.57, p<.01)$.

The results also showed some associations of $\mathrm{CO}$ with the insula and amygdala, which are parts of the limbic system and are implicated in empathy. The amygdala is directly implicated in emotions (especially fear), whereas the insula is a pathway to the amygdala from the $\mathrm{MN}$ system (e.g., Carr et al. 2003). The findings reveal significant positive correlations with $\mathrm{CO}$ scores: left amygdala ([-22 2-20], $r=.49, p<.05)$, and left insula ( $\left.\left[\begin{array}{lll}-40 & -2 & 8\end{array}\right], r=.50, p<.05\right)$. We did not present these findings in Table 7 because the $\mathrm{k}$ cluster sizes were small ( 8 for the amygdala, 3 for the insula). Nevertheless, it can be argued that smaller cluster sizes might be appropriate for smaller regions of the brain, such as the amygdala (see Huettel et al. 2008, p. 361, for a discussion of thresholds for cluster size).

Figure 4 ( $a$ and $b$ ) depicts the activations summarized in Table 7 in atlas maps; all are from the left hand side. The precuneus (right) is symmetrically located on the other side of the brain (however not visible on the map). All nine significantly activated regions are displayed in their respective areas corresponding to their voxel sizes and highlighted in color. The designations " $\mathrm{R}$ " and " $\mathrm{L}$ " refer to 
Table 7 Brain activations: Detection of negative emotions minus neutral emotions for high minus low CO score

\begin{tabular}{|c|c|c|c|c|c|c|c|c|}
\hline \multirow[b]{2}{*}{ Anatomical Region } & \multirow[t]{2}{*}{ Function } & \multirow{2}{*}{$\begin{array}{l}\text { Hemisphere } \\
\text { L/R }\end{array}$} & \multicolumn{3}{|c|}{ MNI coordinates } & \multirow{2}{*}{$\begin{array}{l}\text { Cluster size } \\
\mathrm{k}\end{array}$} & \multicolumn{2}{|l|}{ Statistics } \\
\hline & & & $\mathrm{x}$ & $\mathrm{y}$ & $\mathrm{z}$ & & Z-value & $r$ \\
\hline 1. Supplemental motor area & Mirror Neuron & $\mathrm{R}$ & 2 & -2 & 52 & 67 & $3.12^{\#}$ & $.55^{* *}$ \\
\hline 2. Precentral gyrus & Mirror Neuron & $\mathrm{R}$ & 62 & 6 & 24 & 858 & $4.91^{\#}$ & $.72^{* *}$ \\
\hline 3. Postcentral gyrus & Mirror Neuron & $\mathrm{R}$ & 48 & -20 & 62 & 1051 & $4.18^{\#}$ & $.67^{* *}$ \\
\hline 4. Pars opercularis/pars triangularis & Mirror Neuron & $\mathrm{R}$ & 62 & 6 & 22 & 267 & $4.80^{\#}$ & $.72^{* *}$ \\
\hline 5. Precuneus & Executive processes & $\mathrm{R}$ & 10 & -76 & 42 & 237 & $3.25^{\#}$ & $.57^{* *}$ \\
\hline 6. Precuneus & Executive processes & $\mathrm{L}$ & -12 & -42 & 76 & 22 & $3.23^{\#}$ & $.57^{* *}$ \\
\hline 7. Inferior parietal lobule & Perception & $\mathrm{R}$ & 26 & -56 & 50 & 40 & $3.25^{\#}$ & $.54 * *$ \\
\hline 8. Superior parietal lobule & Perception & $\mathrm{R}$ & -46 & 66 & 68 & 26 & $3.25^{\#}$ & $.68^{* *}$ \\
\hline 9. Fusiform gyrus & Face Recognition & $\mathrm{L}$ & -34 & -76 & -16 & 19 & $3.21 \#$ & $.57 * *$ \\
\hline
\end{tabular}

Note: $*=p<.05, * *=p<.01, \#=p<.05$ corrected for multiple comparisons at cluster level with small volume corrections of a sphere of 5 mm radius

right and left areas of the brain, respectively. The bottom

(a) Location: Surface of the brain

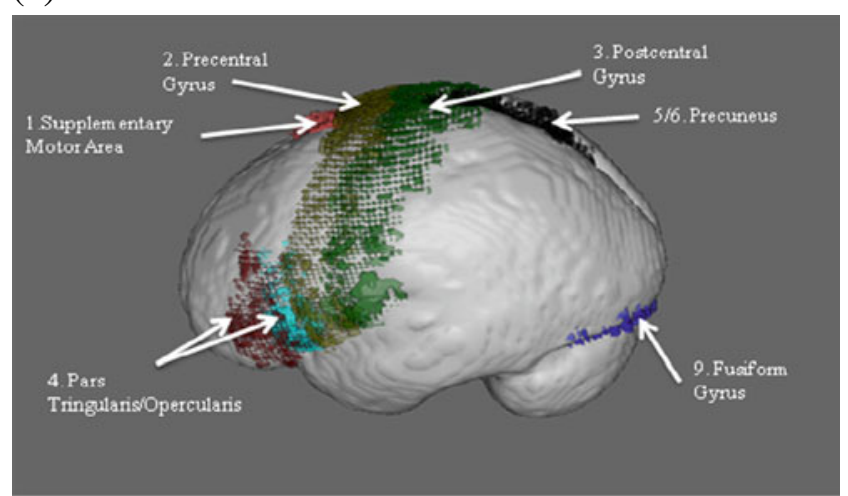

(b) Location: Medial to the brain

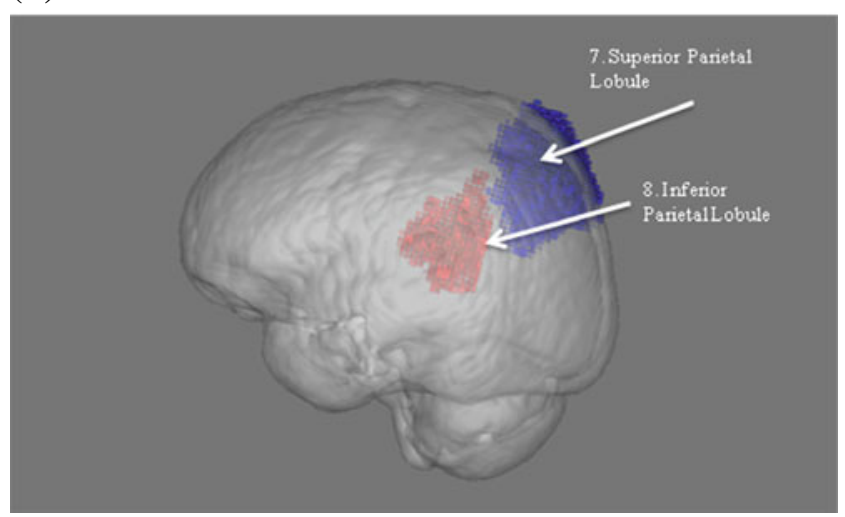

Fig. 4 Contrast activation maps (negative minus neutral facial stimuli). a Location: Surface of the brain. b Location: Medial to the brain. Note: These two atlas maps present the associated areas of the MN network in the condition "Neutral stimuli minus Negative facial stimuli". The areas are visualized in colors in order to enhance the contrast between them. The numbered areas correspond to the numbers used in Table 7. Map a shows the six areas that can be seen on the surface of the brain. Map b depicts a more transparent brain to show the two areas located medial to the brain rows in each sub-figure are views of brain sections from the top.

It is important to observe the positive correlations with the scores for the $\mathrm{CO}$ items. These mean that the brain areas associated with empathy are activated more strongly the higher the $\mathrm{CO}$. In other words, the $\mathrm{MN}$ system automatically tunes more into the other person, one aspect of empathy.

A small number of associations were found between scores on the $\mathrm{CO}$ scale and activation of brain regions for the contrast between observation of negative emotions and geometric shapes. As these findings are not as informative as those presented in Table 7, they are not presented here. No significant results were found between scores for SO items and activation of brain regions for the contrast between observation of negative emotions and any other condition. We offer reasons for this in the next section. No significant findings occurred for positive emotions. Finally, as expected, no significant correlations between $\mathrm{SO}$ or $\mathrm{CO}$ scores for both positive and negative emotions occurred during the imitation task.

\section{Discussion}

As predicted, $\mathrm{CO}$ is related positively to activation of the $\mathrm{MN}$ system that constitutes part of the empathetic response. Similarly, $\mathrm{CO}$ is related positively to activation of the insula and amygdala, which are part of felt emotional aspects of empathy. However, no significant results were found concerning the contrast of negative emotions minus neutral stimuli (consequently, the other contrasts as well) and the scores on the SO items. Clearly, and making a leap from this fMRI experiment to sales-customer interactions, $\mathrm{CO}$ is related to processes involved in inferring the beliefs, desires, and intentions of others and resonating with the feelings of others, 
while at the same time putting oneself in the shoes of others, so to speak. Note that salespeople scoring high on SO do not exhibit any of these activations whatsoever. These are remarkable findings that seem to validate the meaning of $\mathrm{CO}$ and SO. Extrapolating from a simple experiment to a selling situation, in concrete terms this finding supports Saxe and Weitz's (1982) assertion that SO salespeople would rather exert pressure on customers than seek to understand them (e.g., by encouraging customers to discuss their needs with them). On the other hand, CO seems to be decidedly empathetic.

\section{General discussion}

Customer orientation implies that salespeople are passionately curious about the customer's needs so that they can propose a solution that meets and matches these needs. Selling orientation involves persuasion, exerting pressure, stretching the truth, or even ignoring certain needs of customers (Saxe and Weitz 1982, p. 343) in order to make a customer buy. Rather than focusing on an outside-in approach (using paper and pencil psychology-based antecedents, such as intrinsic motivation or empathy) to study $\mathrm{CO}$ versus $\mathrm{SO}$, we sought to focus on an inside-out approach: we focused on biomarkers derived from the field of genetics and activations of brain regions as measured by fMRI methods.

What do the results of our three studies imply and what is the common picture or idea we might extract from them? We first suggested in Study 1 that industrial salespeople operate in a knowledge-intensive economy as knowledge brokers (and mini-marketers) who constantly seek knowledge from various sources. They apply knowledge gained by analogical reasoning to solve the problems they elicit from customers which, in turn, leads to commercial gains. We termed this process broadly as opportunity recognition. Considering that CO should influence opportunity recognition, we developed an opportunity recognition scale and showed that $\mathrm{CO}$ is strongly related to opportunity recognition, but $\mathrm{SO}$ is not. From there, we concluded that salespeople with higher $\mathrm{CO}$ tend to engage avidly in conversations with customers (e.g., various members of the buying center) and in other professional situations (e.g., trade shows, social networks), striving to enrich their knowledge so as to come up with viable commercial solutions. It is this passion, curiosity, and drive to attain commercial results that inspired us to focus our inquiry on the dopamine system as well, since the operation of this system is especially known to be involved in novelty seeking, the pursuit of commercial success (incentive salience), chasing new challenges, risk taking, and the satisfaction that comes from this searching process (see Berns (2005) for a nice description of these processes and Nicolaou and Shane (2009) for further insights in the entrepreneurial area).

In Study 2, we discovered that CO is significantly related to a polymorphism of the $D R D 4$ gene (especially the 7-repeat gene), whereas no such association was found for SO. People with a DRD4 7-repeat gene are known to be creative and explorative as well as entrepreneurial, attributes closely aligned with opportunity recognition and seeking commercial success. This is consistent with the meaning and implications of $\mathrm{CO}$. Note that $\mathrm{CO}$ was not associated with the DRD2 polymorphism (known to be associated with cognitive inflexibility, addiction, inability to switch strategies, and antisocial behavior), whereas $\mathrm{SO}$ was marginally related $(p<.07)$. This, too, is generally consistent with the meaning and implications of SO.

To understand why $\mathrm{CO}$ relates to opportunity recognition and novelty seeking, we examined whether empathy and related brain processes are associated with $\mathrm{CO}$. Therefore, in Study 3, we focused on emotional aspects of empathy and the MN system that is known to be a precursor of empathic understanding. $\mathrm{CO}$ was found to be related to the activation of the MN system, as well as to other nuclei related to empathy, when observers were confronted with negative faces (with neutral faces subtracted in the analysis by $\mathrm{fMRI}$ activation). This suggests that salespeople high in CO tune in to customers' pain and indications of resistance, and (as Study 1 shows) they are good at relating relevant knowledge when interacting with customers and thus excel in opportunity recognition. Note that SO was found to be unrelated to the MN system and emotional aspects of empathy in the sense that neither a greater proclivity to sell, irrespective of customer needs, nor a strong inclination to use deceptive tactics (e.g., stretching the truth) are related to activation of brain regions in automatic resonance and empathy.

As we suggested at the beginning of this paper, biomarkers provide us with insights into $\mathrm{CO}$ versus $\mathrm{SO}$ that are complementary to the existing literature. Having studied two classes of biomarkers, we might better understand earlier work (see introduction) which has found that salespeople with high $\mathrm{CO}$ are intrinsically motivated and empathic risk takers who are willing to miss out on short-term sales in preference to understanding the customer's problems and to securing long-term business relationships. At first sight, these coarsely grained explanations might seem incoherent. However, our results, derived from an analysis of finely grained biomarkers, provide answers to reasons why some people engage in $\mathrm{CO}$ while others are more likely to engage in SO. Note that these antecedents refer to common biological roots. We believe that these biomarkers bring coherence to the outside-in explanations found in paper and pencil-based psychological research: salespeople high in $\mathrm{CO}$ are constantly willing or eager to 
learn from customers (understand their needs) and are interested in learning about the world (intrinsic motivation) so as to present commercially viable solutions to satisfy customers. All of this involves regulation by the dopamine system.

A continuous interest in customers' problems and seeking possible commercially viable solutions entails risk. Interestingly, risk taking is a phenotype or characteristic of people with the DRD4 7-repeat polymorphism (e.g., Dreber et al. 2009). Ultimately we agree with the basic insight that Saxe and Weitz (1982) propose when they state that the benefits of $\mathrm{CO}$ selling must be weighed against its costs, such as reflected in (a) the salesperson's time spent identifying customers' problems and solutions, (b) reduced margins or increased service costs entailed in satisfying customers, and (c) lost sales (at least in the short run) that might have been achieved with more aggressive selling approaches (see Franke and Park 2006, p. 694). In an era when salespeople constantly have to come up with sales results in order to meet their firm's sales objectives, and their results are monitored by their firm's CRM and SFA systems, it is easy to succumb to SO because salespeople with $\mathrm{CO}$ do not always sell quickly (Saxe and Weitz 1982).

How do salespeople tune in their knowledge and curiosity to specific customers? What we have learned about how MN systems operate gives us insights into this. MN system activation is a precursor of felt empathy, and thus attunement to customers and their pain or resistance is vital. We suggest that when salespeople tune in to customers, they might be more likely to elicit useful cues, which thereupon trigger the salespeople's knowledge-gathering structures. Natural curiosity, the passion and drive to find opportunities (as implicated by dopamine system activation), and the ability to tune in to cues that customers express (and thus motivate them to express even more cues), distinguishes salespeople able to engage in $\mathrm{CO}$ from those who are not.

\section{Biomarkers in sales research}

Although we believe that ours is one of the first studies to use biomarkers as research tools to study personal selling (cf. Dietvorst et al. 2009), our research results are not entirely different from those found in the existing literature; rather, they complement previous findings. The field of selling has not incorporated biomarker applications into policies and applications, and their use as novel research tools may provoke more questions than answers at this time. The use of biomarkers raises certain questions. For example, does it mean that people with the $D R D 4$ 7-repeat polymorphism have a natural advantage to become salespeople; in other words, are they born to sell? Alternatively, should we use fMRI scanning techniques to select, train, and coach salespeople? We briefly address these questions below.

Genetic biomarkers are inherited and cannot be changed, by definition. However, biological mechanisms are not rigidly attuned to the roles people actually play in society, as the old nature versus nurture adage implies. We suggest that people with the DRD4 gene possess natural curiosity and will engage more easily in opportunity recognition than those without the gene. However, having a proclivity for curiosity does not mean that a salesperson will automatically engage in $\mathrm{CO}$. Effective $\mathrm{CO}$ must be learned, and it is trainable (e.g., salespeople can learn to ask appropriate questions and engage customers strategically in sales conversations, study their industry environment). Naturally, curious people may learn more easily and adopt $\mathrm{CO}$, as they are driven to learn and hone their skills to achieve rewards.

As for the MN system, there is substantial evidence that some people fall significantly above and below the norms for having mirror neurons, and the functioning of the MN system differs across people systematically. There is evidence that the MN system can be trained or fine-tuned to a certain extent. Perhaps, as salespeople gain experience (through curiosity, and trial and error, as we suggest), they attune their MN system to their social environment. At present, it is not sensible to make any stronger statements on this notion as people with above average MN system functioning may not necessarily have a strong need to seek novelty or the rewards stemming from effective selling. There may be an interaction between DRD4 7R gene and MN system propensities. We can only surmise that salespeople who exhibit strong $\mathrm{MN}$ activation and curiosity will be more likely to engage in $\mathrm{CO}$, but this remains to be studied. Equally, not all empathic people will be good salespeople, but being empathic and able to tune sensitively into specific customer needs and desires should help one engage in CO. Interestingly, research shows that dopamine system regulation is involved in social attunement (Skuse and Gallagher 2009). More specifically, the literature shows that attunement to other people involves the production of oxytocin. This hormone triggers the dopamine system, which, in turn, facilitates greater attunement to others (e.g., the proclivity to interact with people and study facial expressions).

Our results from this study are in line with these findings, yet fuller substantiation requires another research strategy to look even deeper into the neurological mechanisms: the hormone production of salespeople with high versus low CO (and SO) should be studied as salespeople interact with customers. This is becoming feasible with new methods. Future research could look for biomarkers and not merely more genes (e.g., $O X T$, a gene for oxytocin) 
but more fMRI-based experiments and hormonal studies (see Heaphy and Dutton 2008, for such an attempt in organizational science).

It should be noted that the DRD4 gene is known to be associated with ADHD and is found in overly creative and easily distracted people (e.g., Hartmann and Palladino 2004). It is possible that some salespeople might become too curious or enamored with novelty seeking and therefore be less likely to close a deal-which might explain why some salespeople fail to get results (e.g., Franke and Park 2006, p. 694). However, the salespeople in our sample with the DRD4 gene and its $7 \mathrm{R}$ variant scored high on $\mathrm{CO}$ and thus by implication (and in accordance with the findings in Study 1) should exhibit greater opportunity recognition. In a sense, the ability to cope with potentially dysfunctional abilities is a key factor in selling. If we are to understand in depth how $\mathrm{CO}$ operates, we should also study how salespeople with high $\mathrm{CO}$ are managed; it seems that salespeople high in $\mathrm{CO}$ may require a particular supportive environment (i.e., one not overly shortterm oriented) in which they can perform unhindered so as to meet specific performance expectations.

\section{Implications for managers}

Apparently when salespeople engage in $\mathrm{CO}$ to any extent, they tend to interact with customers with less insincere camaraderie or stretch the truth less than do salespeople with SO. They are driven by curiosity to engage in opportunity recognition. Sales managers should select salespeople with these goal orientations in mind. During job interviews and behavioral assessments, managers should explore whether salespeople are really empathetic sellers or merely selfish "tellers." They can deduce CO capabilities by asking candidates how they would approach a problem or from looking at CVs, biographies, hobbies, recommendations, personal statements, and personal interviews. Sales managers should also look at the extent to which salespersons are interested in exploring their industry and new developments within it. Finally, the sales manager must discover whether the salesperson has empathy, as opportunity recognition begins with recognizing the pain and resistance of the customer. Empathy may show up in social behaviors, such as possession of friends, social network, or interest in a coaching position for people who do sports, volunteer work, etc.

Once salespeople are hired, sales managers should allow them to explore new avenues. Since engaging in $\mathrm{CO}$ is a risky business and might not always immediately result in generating new or more business, sales managers should also guide their sales staff in two ways. First, they can let salespeople high in $\mathrm{CO}$ work together (team selling) with salespeople who are results-driven (which does not necessarily mean being high in SO). Note that salespeople with high $\mathrm{CO}$ are probably good team players, as their natural ability to attune with others might help them function well in a peer group of coworkers. Secondly, sales managers should not micromanage salespeople high in $\mathrm{CO}$ but should allow them to explore new avenues as far as possible (e.g., Bonney and Williams 2009; Stock and Hoyer 2005;) and give them the psychological safety to experiment and take risks (e.g., Edmonson 2002). The salesperson-sales manager interaction should be more like a coaching/ mentoring relationship than a controlling relationship (Pettijohn et al. 2002) to promote the adoption of CO. Coaching is important because too much curiosity could distract a salesperson; it needs to be channeled.

Given the fact that firms want their salespeople to share knowledge, so that the knowledge inherent in the firm can flow to other companies, salespeople high in $\mathrm{CO}$ should be given the chance to formally share with their colleagues the knowledge they have gained from customers and the market. Indeed, their experience and ability to signal new trends is of such importance that the firm should consider getting them to help with the development of new products (Ernst et al. 2010). Once again, natural curiosity and opportunity recognition skills may not bring many more or new customers, per se, but they can bring new market insights to the firm. Also noteworthy is the fact that salespeople high in $\mathrm{CO}$ might well be good team players who tend not to offend other colleagues working in-house, such as in customer support departments (which is an opportunity for research topic). An additional side effect of natural curiosity is that inquisitive salespeople might learn faster (their genes almost force them to do this) than their managers (who might be less curious). This might provide a threat to (insecure) sales managers, but it should be seen as an opportunity for the firm. Sales managers would be wise to create platforms (knowledge sharing sessions) in their firm so that they themselves, as well as other colleagues, can assimilate in-house knowledge in the sales group as well as the firm's other departments. In doing so, they might test the future leadership abilities of salespersons high in $\mathrm{CO}$. Note, too, $\mathrm{CO}$ rubs off and can promote positive organizational dividends in terms of company morale and esprit de corps.

Acknowledgements The authors would like to express their gratitude to Dr. Caroline Schraa-Tam for help in data analysis in Study 3 and to Isam-neuroscience at the Erasmus School of Economics which sponsored the research

Open Access This article is distributed under the terms of the Creative Commons Attribution Noncommercial License which permits any noncommercial use, distribution, and reproduction in any medium, provided the original author(s) and source are credited. 


\section{Technical Appendix 1}

This appendix contains the technical details of the DNA analysis used in Study 2.

Buccal swab was used to obtain DNA, DRD4 $48 \mathrm{bp}$ VNTR and DRD2 Taq1a; the PCR reaction contained $1 \mathrm{x}$ Q-Solution (Qiagen), 1x Buffer (Qiagen), $1 \mu \mathrm{M}$ Primer 1 (5'GCGACTACGTGGTCTACTCG 3'), $1 \mu \mathrm{M}$ Primer 2 (5' AGGACCCTCATGGCCTTG 3'), $200 \mu \mathrm{M}$ dATP, dTTP, dCTP and $100 \mu \mathrm{M}$ dITP and dGTP, 0.3 units HotStar Taq (Qiagen), $1 \mu$ of DNA template, in a total volume of $10 \mu \mathrm{l}$. Thermocycler conditions included $15 \mathrm{~min}$ at $95^{\circ}$ to activate the enzyme and denature the DNA, 40 cycles of $1 \mathrm{~min}$ denaturation at $94^{\circ}, 1 \mathrm{~min}$ annealing at $55^{\circ}, 1.5 \mathrm{~min}$ extension at $72^{\circ}$, followed by one cycle of $10 \mathrm{~min}$ extension at $72^{\circ}$. A $4 \mathrm{R}$ PCR product is $475 \mathrm{bp}$. Samples were visualized under UV on 1.4-2.0\% ethidium bromide agarose gels with a $100 \mathrm{bp}$ ladder. Some gels were placed in a $1 \mathrm{x}$ boric acid bath for 10-15 min to increase contrast and allow better visualization of the different alleles. DRD4 48 bp and DRD2 Taq1a genotyping had a $100 \%$ success rate, after conducting re-testing once within two subjects.

Subjects were instructed to rinse their mouths out with water before swabbing. The DRD2 genotype was assessed as an additive trait in the analysis; this means that the presence of a $\mathrm{T}(\mathrm{A} 1)$-allele $=1$, No $\mathrm{T}$-allele $=0$. The allele frequencies are depicted in Table 3 (DRD4) and Table 7 (DRD2). The DRD4 genotype was also assessed as an additive trait in the analysis; $7 \mathrm{R}$ absence $=0$, presence of at least a $7 \mathrm{R}=1$. The genotype distribution was tested against expected genotype frequencies according to the Hardy-Weinberg Equilibrium (HWE) model. This law states that there is a simple relationship between the allele frequencies and the genotype frequencies (Guo and Thompson 1992). The genotypes in our population were in agreement with the Hardy-Weinberg proportions. DRD2: $\chi 2=1.1165 p$-value $=0.29$, one-sided; $D R D 4: \chi 2=$ $0.3915 p$-value $=0.53$, one-sided.

\section{Technical Appendix 2}

This appendix presents the technical details of the fMRI research study.

\section{Experimental design and fMRI research}

The experimental stimuli consisted of full-face, full-color video clips of five males and five females displaying various emotional states (anger, disgust, happiness, surprise, and neutrality). The control stimuli were clips of moving geometrical shapes. Thus, the four experimental conditions were: (1) positive emotional faces: happy and surprised, (2) negative emotional faces: angry and disgust, (3) neutral faces, and (4) moving geometrical shapes. Each clip was played for $3 \mathrm{~s}$ in 12-second blocks of three clips plus interstimulus intervals of $1 \mathrm{~s}$. Each block consisted of either only positive, negative, or neutral emotions or moving geometrical shapes. Counterbalanced versions of the stimuli were employed. The blocks allowed us to explore two hypotheses: (1) positive and negative faces minus moving geometrical shapes and (2) positive and negative faces minus neutral faces. This design is similar to that employed frequently in the neuroscience literature (e.g., Wicker et al. 2003).

\section{fMRI acquisition}

All imaging was performed on a 3 T MRI scanner (General Electric, Milwaukee, USA) using a dedicated eightchannel head coil. For the anatomical image, a 3D high resolution inversion recovery fast spoiled gradient recalled echo sequence (echo time (TE)/repetition time $(\mathrm{TR}) /$ inversion time $=2.1 / 10.4 / 300 \mathrm{~ms}$, flip angle $=18^{\circ}$, matrix $=416 \times 256$, field of view $(F O V)=25 \mathrm{~cm}$, slice thickness $1.6 \mathrm{~mm}$ with $50 \%$ overlap) was required.

For functional imaging, a single-shot gradient-echo echo-planar imaging (EPI) sequence in transverse orientation was used in each study that is sensitive to blood oxygenation level dependent (BOLD) contrast. The imaging volume covered the entire brain (TR/TE 3000/ $30 \mathrm{~ms}$. $64 \times 96$ matrix with a rectangular field of view of $22 \mathrm{~cm}, 2.5 \mathrm{~mm}$ slice thickness, 39 contiguous slices; voxel size of $3.5 \times 3.0 \times 2.5 \mathrm{~mm}^{3}$ ). Acquisition time was 10:45 min with a time series of 210 imaging volumes (including $15 \mathrm{~s}$ of dummy scans that were discarded).

The experiment was performed in near darkness with all lights turned off except for the video projector. Visual stimuli were shown by means of back projection with a video projector onto a translucent screen in front of the scanner. Participants viewed this screen with a mirror system on top of the head coil. The total field of view extended $21^{\circ}$ horizontally and $17^{\circ}$ vertically. Stimuli were presented by the stimulation software package Presentation (Neurobehavioral Systems).

Functional image analysis

The functional imaging data were analyzed using statistical parametric mapping software (SPM 5, distributed by the Wellcome Department of Cognitive Neurology, University College London, UK) implemented in MATLAB (Version 6.5, Mathworks, Sherborn, MA, USA). Motion correction and co-registration were done according to the methodology provided by SPM5. Brain volumes were normalized to the 
standard space defined by the Montreal Neurological Institute (MNI) template. The normalized data had a resolution of $2 \times 2 \times 2 \mathrm{~mm}$ and were spatially smoothed with a three-dimensional isotropic Gaussian kernel, with a full width half maximum of $8 \mathrm{~mm}$.

Statistical parametric maps were calculated for each subject. Movement parameters resulting from the realignment preprocessing were included as regressors of no interest to further reduce motion artifacts. The model was estimated with a high pass filter with a cut-off period $128 \mathrm{~s}$. For each participant, contrast maps were calculated between each condition. The individual contrast maps were used for second level random effects (group) analysis in the regression analyses.

Because the hypotheses for Study 3 are based on activity in previously defined regions, regression analyses were performed to investigate the differences in brain activation in a Regions-of-Interest (ROI) approach for partic- ipants scoring high versus low on both $\mathrm{CO}$ and SO. ROI analysis significantly decreases the multiple comparison problem. Therefore, a less strict correction is used in this study. Specifically, the following key regions of the brain were measured: the mirror neuron system (the precentral gyrus, pars opercularis, and TPJ), in conjunction with the insula and the amygdala (which is activated when emotions are involved). In addition, focus was also placed on top-down processes: the precuneus as well as the TPJ. At these locations, significance of the interactions was tested by constraining the analysis to the ROI derived from the WFU-PickAltas software package. Individual scores on $\mathrm{CO}$ and $\mathrm{SO}$ were entered as covariates in these analyses. Last, we analyzed the correlations between the SO- and CO-item scores with the significant activations found in the contrast of negative faces minus neutral faces.

\section{Technical Appendix 3}

Table 8 Means, standard deviations, and correlations of indicators for customer orientation $(\mathrm{CO})$, sales orientation (SO), motivation to learn from customer (MLC), contextual knowledge formation (CKF), and buying center knowledge formation (BCKF)

\begin{tabular}{lrrrrrrrrrr}
\hline & CO1 & CO2 & \multicolumn{1}{c}{ SO1 } & SO2 & MLC1 & MLC2 & CKF1 & CKF2 & BCKF1 & BCKF2 \\
\hline CO1 & 1.00 & & & & & & & & & \\
CO2 & .77 & 1.00 & & & & & & & & \\
SO1 & .41 & .39 & 1.00 & & & & & & & \\
SO2 & .39 & .48 & .68 & 1.00 & & & & & & \\
MLC1 & .51 & .56 & .34 & .31 & 1.00 & & & & & \\
MLC2 & .49 & .52 & .33 & .30 & .88 & 1.00 & & & & \\
CKF1 & .33 & .41 & .14 & .26 & .46 & .45 & 1.00 & & & \\
CKF2 & .33 & .45 & .12 & .21 & .48 & .49 & .77 & 1.00 & & \\
BCKF1 & .46 & .47 & .21 & .17 & .43 & .46 & .39 & .44 & 1.00 & \\
BCKF2 & .31 & .38 & .16 & .12 & .45 & .44 & .37 & .37 & .72 & 1.00 \\
Means & 6.19 & 6.22 & 5.05 & 5.46 & 5.93 & 5.87 & 5.47 & 5.73 & 5.31 & 5.30 \\
Std Dev & .75 & .72 & 1.22 & 1.05 & .83 & .82 & .88 & .94 & 1.10 & 1.12 \\
\hline
\end{tabular}

\section{References}

Bagozzi, R. P., \& Edwards, J. (1998). A general approach for representing constructs in organizational research. Organizational Research Methods, 1(1), 45-87.

Bagozzi, R. P., \& Heatherton. (1994). A general approach to representing multifaceted personality constructs: application to state self-esteem. Structural Equation Modeling: A multidisciplinary Journal, 1(1), 35-67.

Baron, R., \& Ward, T. A. (2004). Expanding entrepreneurial cognition's toolbox: potential contributions from the field of cognitive psychology. Entrepreneurship Theory and Practice, 28 (6), 553-573.

Berns, G. (2005). Satisfaction: sensation seeking, novelty, and the science of finding true fulfillment. New York: Holt.

Berridge, K., \& Robinson, T. (1998). What is the role of dopamine in reward: hedonic impact, reward learning, or incentive salience? Brain Research and Brain Research Review, 28(3), 309-369.
Blake, R. R., \& Mouton, J. S. (1970). The grid for sales excellence. New York: McGraw-Hill.

Bonney, L. F., \& Williams, B. C. (2009). From products to solution: the role of salesperson opportunity recognition. European Journal of Marketing, 43(7-8), 1032-1052.

Carr, L., Iacoboni, M., Dubeau, M., Mazziotta, J. C., \& Lenzi, G. L. (2003). Neural mechanisms of empathy in humans: a relay from neural systems for limitation to limbic areas. PNAS, 100, $5497-$ 5502.

Cavanna, A. E., \& Trimble, M. R. (2006). The precuneus: a review of its functional anatomy and behavioural correlates. Brain, 129, 564-583.

Cheng, Y., Chou, K.-H., Decety, J., Chen, I.-Y., Hung, D., Tzeng, O. J.-L., et al. (2009). Sex differences in the neuroanatomy of human mirror neuron system: a voxel-based morphometric investigation. Neuroscience, $158,713-720$.

Cloninger, R. C. (2004). Feeling good: the science of well-being. Oxford: Oxford University Press.

Congdon, E., Lesch, K. P., \& Canli, T. (2008). Analysis of DRD4 and $D A T$ polymorphisms and behavioral inhibition in healthy adults: 
Implications for impulsivity. American Journal of Medical Genetics. Part B, Neuropsychiatric Genetics, 147B(1), 27-32.

Cross, R., \& Sproull, L. (2004). More than an answer: Information relationships for actionable knowledge. Organization Science, $15,446-462$.

Dapretto, M., Davies, M. S., Pfeifer, J. H., Scott, A. A., Sigman, M., Bookheimer, S. Y., et al. (2006). Understanding emotions in others: mirror neuron dysfunction in children with autism spectrum disorders. Nature Neuroscience, 9(1), 28-30.

Davis, M. H. (1994). Empathy: a social psychological approach. Dubuque: Brown and Benchmark.

Dawes, P. L., Lee, D. Y., \& Dowling, G. R. (1998). Information control and influence in emergent buying centers. Journal of Marketing, $62,55-68$

Decety, J., \& Jackson, P. L. (2004). The functional architecture of human empathy. Behavioral and Cognitive Neuroscience Reviews, 3(2), 71-100.

Decety, J., \& Lamm, C. (2006). Human empathy through the lens of social neuroscience. The Scientific World Journal, 6, 1146-1163.

Decety, J., \& Lamm, C. (2007). The role of the right temporoparietal junction in social interaction: How low-level computational processes contribute to meta-cognition. The Neuroscientist, 13, 580-593.

Dietvorst, R. C., Verbeke, W. J., Bagozzi, R. P., Yoon, C., Smits, M., \& van der Lugt, A. (2009). A salesforce-specific theory of mind scale: tests of its validity by multitrait-multimethod matrix, confirmatory factor analysis, structural equation models, and functional magnetic resonance imaging. Journal of Marketing Research, 46(5), 653-668.

Dreber, A., Apicella, C. L., Eisenberg, D. T., Garcia, J. R., Zamore, R. S., Lum, J. K., et al. (2009). The 7R polymorphism in the dopamine receptor $\mathrm{D}_{4}$ gene $(D R D 4)$ is associated with financial risk taking in men. Evolution and Human Behavior, 30, 85-92.

Eades, K. M. (2004). The new solution selling. New York: McGraw-Hill.

Ebstein, R. P., Novick, O., Umansky, R., Priel, B., Osher, Y., Blaine, D., et al. (1996). Dopamine D4 receptor $(D 4 D R)$ exon III polymorphism associated with the human personality trait of novelty seeking. Nature Genetics, 12, 78-80.

Edmonson, A. C. (2002). The local and variegated nature of learning I organizations: a group-level perspective. Organization Science, $13,128-146$

Edmonson, A. C., \& Williams Woolley, A. (2003). Understanding outcomes of organizational learning interventions. In M. Easterby-Smith \& M. A. Lyles (Eds.), The Blackwell handbook of organizational learning and knowledge management (pp. 185-211). Oxford: Blackwell.

Eisenberg, D. T., MacKillop, J., Modi, M., Beauchemin, J., Dang, D., Lisman, S. A., et al. (2007). Examining impulsivity as an endophenotype using a behavioral approach: a DRD2 TaqI A and DRD4 48-bp VNTR association study. Behavioral and Brain Functions, 3(2).

Eisenberg, N. (2000). Emotion, regulation, and moral development. Annual Review of Psychology, 51, 665-697.

Ernst, H., Hoyer, W. D., \& Rübsaamen, C. (2010). Sales, marketing, and research and development cooperation across new product development stages: implications for success. Journal of Marketing, 74 (5), 80-92.

Franke, G. R., \& Park, J. (2006). Salesperson adaptive selling behavior and customer orientation: a meta-analysis. Journal of Marketing Research, 43, 693-702.

Gallese, V. (2003). The manifold nature of interpersonal relations: the quest of a common mechanism. Philosophical Transactions of the Royal Society London B Biological Sciences, 358, 517-528.

Gregoire, D., Barr, P. S., \& Shepherd, D. A. (2010). Cognitive processes of opportunity recognition: the role of structural alignment. Organization Science, 21(2), 413-431.
Guo, S. W., \& Thompson, E. (1992). Performing the exact test of Hardy-Weinberg proportion for multiple alleles. Biometrics, 48, 361-372.

Hallowell, E., \& Ratey, J. J. (1994). Driven to distraction: recognizing and coping with attention deficit disorder from childhood through adulthood. New York City: Touchstone.

Hartmann, T., \& Palladino, L. J. (2004). The Edison gene: ADHD and the gift of the hunter child. New York: Park Street Press.

Heaphy, E. D., \& Dutton, J. E. (2008). Positive social interactions and the human body at work: linking organizations and physiology. Academy of Management Review, 33(1), 137-162.

Holyoak, K. J. (1985). The pragmatics of analogical transfer. In G. $\mathrm{H}$. Bower (Ed.), The psychology of learning and motivation ((pp, Vol. 19, pp. 59-87). New York: Academic.

Homburg, C., Wieseke, J., \& Bornemann, T. (2009). Implementing the marketing concept at the employee-customer interface: the role of customer need knowledge. Journal of Marketing, 73(July), 6481.

Huettel, S. A., Song, W. A., \& McCarthy, G. (2008). Functional magnetic resonance imaging (2nd ed.). Massachusetts: Sinaur.

Iacoboni, M. (2009). Imitation, empathy, and mirror neurons. Annual Review of Psychology, 60, 653-670.

Iacoboni, M., \& Dapretto, M. (2006). The mirror neuron system and the consequences of its dysfunction. Nature Reviews Neuroscience, 7 , 942-951.

Johnson, J. L., Sohl, R. S., \& Grewal, R. (2004). The role of relational knowledge stores in interfirm partnering. Journal of Marketing, $68,21-36$.

Kohli, A. (1989). Determinants of influence in organization buying: a contingency approach. Journal of Marketing, 53(July), 50-65.

Kreek, M. J., Nielsen, D. A., Butelman, E. R., \& LaForge, S. K. (2005). Genetic influences on impulsivity, risk taking, stress responsivity and vulnerability to drug abuse and addiction. Nature Neuroscience, 8(11), 1450-1457.

Lamm, C. C., Batson, D., \& Decety, J. (2007). The neural substrate of human empathy: effects of perspective-taking and cognitive appraisal. Journal of Cognitive Neuroscience, 19, 42-58.

Leigh, T., Pullins, E. B., \& Comer, L. B. (2001). The top ten sales articles of the 20th century. Journal of Personal Selling and Sales Management, 21(Fall), 217-27.

Levitt, T. (1986). The marketing imagination. London: Collier MacMillan.

Mayer D, Greenberg HM (1964) What makes a good salesman? Harvard Business Review, July-August, pp 119-125

McCarthy, G., Puce, A., Gore, J., \& Allison, T. (1997). Face-specific processing in the human fusiform gyrus. Journal of Cognitive Neuroscience, 9(5), 605-610.

McClure, S. M., Laibson, D. I., Loewenstein, G., \& Cohen, J. D. (2004). Separate neural systems value immediate and delayed monetary rewards. Science, 306, 503-507.

Mercier, H., \& Sperber, D. (2011). Why do humans reason? Arguments for an argumentative theory. The Behavioral and Brain Sciences, 34, 57-74.

Munafo, M. R., Yalcin, B., Willis-Owen, A. A., \& Flint, J. (2008). Association of the dopamine D4 Receptor (DRD4) gene and approach-related personality traits: meta-analysis and new data. Biological Psychiatry, 63, 197-206.

Nachev, P., Kennard, C., \& Husain, M. (2008). Functional role of the supplementary and presupplementary motor areas. Nature Reviews Neuroscience, 9, 856-869.

Nicolaou, N., Shane, S., Cherkas, L., \& Spector, T. D. (2008). The influence of sensation seeking in the heritability of entrepreneurship. Strategic Entrepreneurship Journal, 2, 7-21.

Nicolaou, N., \& Shane, S. (2009). Can genetic factors influence the likelihood of engaging in entrepreneurial activity. Journal of Business Venturing, 24, 1-22. 
Oberman, L. M., \& Ramachandran, V. S. (2007). The simulating social mind: the role of the mirror neuron system and simulation in the social and communicative deficits of autism spectrum disorders. Psychological Bulletin, 133, 310-327.

Periatt, J. A., LeMay, S. A., \& Chakrabarty, S. (2004). The selling orientation-customer orientation (SOCO) scale: cross validation of the revised version. Journal of Personal Selling and Sales Management, 24, 49-54.

Pettijohn, C., Pettijohn, L., \& Taylor, A. J. (2002). The influence of salesperson skill, motivation, and training on the practice of customer-oriented selling. Psychology and Marketing, 19(9), $743-757$.

Richardson, L. (1994). Stop telling, start selling: how to use customerfocused dialogue to close sales. New York: McGraw-Hill.

Rodan, S., \& Galunic, C. (2004). More than network structure: how knowledge heterogeneity influences managerial performance and innovativeness. Strategic Management Journal, 25, $541-562$.

Saxe, R., \& Weitz, B. A. (1982). The SOCO scale: a measure of the customer orientation of salespeople. Journal of Marketing Research, 19, 343-351.

Singer, T., \& Fehr, E. (2005). The neuroeconomics of mind reading and empathy. The American Economic Review, 95(2), 340-45.

Skuse, D., \& Gallagher, L. (2009). Dopaminergic-neuropeptide interactions in the social brain. Trends in Cognitive Sciences, 13 (1), 27-35.

Stock, R. M., \& Hoyer, W. D. (2005). An attitude behavior model of salespeople's customer orientation. Journal of the Academy of Marketing Science, 33(Fall), 536-552.

Tanner, R. J., Ferraro, R., Chatrand, T. L., Bettman, J. R., \& Van Baaren, R. (2008). Of chameleons and consumption: the impact of mimicry on choice and preferences. Journal of Consumer Research, 34(April), 754-766.

Thomas, R. W., Soutar, G. N., \& Ryan, M. M. (2001). The selling orientation-customer orientation (SOCO) scale: a proposed short form. Journal of Personal Selling and Sales Management, 21(1), 63-68.

Van der Gaag, C., Minderaa, R. B., \& Keysers, C. (2007). Facial expressions: what the mirror neuron system can and cannot tell us. Social Neuroscience, 2, 179-222.

Vargo, S., \& Lusch, R. F. (2004). Evolving to a new dominant logic for marketing. Journal of Marketing, 68(January), 1-17.

Verbeke, W. J., Dietz, B., \& Verwaal, E. (2011). Drivers of sales performance: a contemporary meta-analysis. Have salespeople become knowledge brokers? Journal of the Academy of Marketing Science, 39(3), 407-428.

Vogeley, K., Bussfeld, P., Newen, A., Herrmann, S., Happe, F., Falkai, P., et al. (2001). Mind reading: neural mechanisms of theory of mind and self-perspective. NeuroImage, 14(1), 170181.

Vogeley, K., May, M., Ritzl, A., Falkai, P., Zilles, K., \& Fink, G. R. (2004). Neural correlates of first-person perspective as one constituent of human self-consciousness. Journal of Cognitive Neuroscience, 16(5), 817-827.

Weitz, B. A., \& Bradford, K. D. (1999). Personal selling and sales management: a relationship marketing perspective. Journal of the Academy of Marketing Science, 27(2), 241-255.

Wheng SJ (2009) Alterations in functional connectivity of neural networks in adolescents with autism spectrum disorders doctoral dissertation University of Michigan

Wicker, B., Keysers, C., Plailly, J., Royet, J., Gallese, V., \& Rizzolatti, G. (2003). Both of us disgusted in my insula: the common neural basis of seeing and feeling disgust. Neuron, 40, 655-664.

Wojciulik, E., Kanwisher, N., \& Driver, J. (1998). Covert visual attention modulates face- specific activity in the human fusiform gyrus: fMRI study. Journal of Neurophysiology, 79(January), 1574-1578.

Zuckerman M (1994) Behavioral expressions and biosocial bases of sensation seeking. Cambridge University Press 